\title{
Selective laser melting of high-strength, low-modulus Ti-35Nb-7Zr-5Ta alloy
}

Raghunandan Ummethala ${ }^{1,{ }^{*}}$, Phani S. Karamched ${ }^{2}$, Sokkalingam Rathinavelu ${ }^{3}$, Neera Singh $^{4}$, Akash Aggarwal ${ }^{5}$, Kang Sun ${ }^{6}$, Eugene Ivanov ${ }^{7}$, Lauri Kollo ${ }^{4}$, Ilya Okulov ${ }^{8,9}$, Jürgen Eckert $^{10,11}$, K.G. Prashanth ${ }^{4,10,12, \dagger}$

${ }^{1}$ Department of Metallurgical and Materials Engineering, National Institute of Technology, Andhra Pradesh 534101, India.

${ }^{2}$ Department of Materials, University of Oxford, Parks Road, OX1 3PH, UK.

${ }^{3}$ Advanced Materials Processing Laboratory, Department of Metallurgical and Materials Engineering, National Institute of Technology, Tiruchirappalli 620015, India.

${ }^{4}$ Department of Mechanical and Industrial Engineering, Tallinn University of Technology, Ehitajate tee 5, 19086 Tallinn, Estonia.

${ }^{5}$ Department of Mechanical Engineering, Indian Institute of Technology Kanpur, Kanpur 208016, India. ${ }^{6}$ IFW Dresden, Institut für Komplexe Materialien, Postfach 2701 16, D-01171 Dresden, Germany ${ }^{7}$ Tosoh SMD Inc, Grove City, OH- 43123, USA.

${ }^{8}$ Ural Federal University, Institute of Natural Sciences and Mathematics, 620002 Yekaterinburg, Russia. ${ }^{9}$ Leibniz Institute for Materials Engineering - IWT, Badgasteiner Str. 3, Bremen 28359, Germany.

${ }^{10}$ Erich Schmid Institute of Materials Science, Austrian Academy of Sciences, Jahnstraße 12, A-8700 Leoben, Austria.

${ }^{11}$ Department of Materials Science, Chair of Materials Physics, Montanuniversität Leoben, Jahnstraße 12, A8700 Leoben, Austria.

${ }^{12}$ CBCMT, School of Mechanical Engineering, Vellore Institute of Technology, Vellore 632 014, Tamil Nadu, India.

\begin{abstract}
The state-of-the-art alloys for load-bearing implant applications lack the necessary functional attributes and are largely a compromise between biocompatibility and mechanical properties. While commercial alloys pose long-term toxicity and detrimental stress shielding effects, the newly developed alloys are closing in on the gaps, however, falling short of the desired elastic modulus necessary to rule out stress shielding. In this work, we report the fabrication of a low modulus $\beta$-Ti alloy, Ti-35Nb-7Zr-5Ta (TNZT), by selective laser melting (SLM)
\end{abstract}

Corresponding author(s): * Raghunandan Ummethala - raghu.ummethala@gmail.com and

${ }^{\dagger}$ K.G. Prashanth - kgprashanth@gmail.com 
with optimized laser parameters. The as-prepared SLM TNZT shows a high ultimate tensile strength $(\sim 630 \mathrm{MPa})$, excellent ductility $(\sim 15 \%)$ and a lower elastic modulus ( $\sim 81 \mathrm{GPa})$ when compared to the state-of-the-art cp-Ti and Ti-based alloys. The mechanical performance of the as-printed TNZT alloy has been examined and is correlated to the microstructure (grain structure, phase constitution and dislocation density). It is proposed that a high density of GND (geometrically necessary dislocations), resulting from rapid cooling, in the as-prepared condition strengthens the alloy, whereas the single phase $\beta$-bcc crystal structure results in low the elastic modulus. High grain boundary area and a preferred crystal orientation of $\{200\}$ planes within the bec crystal lattices contribute to an additional drop in the elastic modulus of the alloy. It is shown that the TNZT alloy, processed by SLM, demonstrates the best combination of strength and modulus, illustrating its potential as a promising biomaterial of the future.

Keywords: Ti-35Nb-7Zr-5Ta, biomaterials, selective laser melting, microstructure evolution, elastic modulus 


\section{Introduction}

Metallic materials constitute more than $60 \%$ of the market for bioimplants and are the ideal candidates for load-bearing orthopedic applications owing to their high toughness and fatigue strength. Titanium alloys, in particular, are the most favorable due to their excellent biocompatibility, corrosion resistance, mechanical properties and high strength-to-weight ratio [1-4]. However, the potential toxic effects of elements such as $\mathrm{Al}$ or $\mathrm{V}$ in the most common implant-grade $\mathrm{Ti}(\alpha+\beta)$ alloys like Ti-6Al-4V and Ti-6Al-7Nb kindled interest in developing better and safer alternatives. They possess elastic modulus $(\sim 110 \mathrm{GPa})$ higher than that of natural bone (7-30 GPa) and when coupled together, instigates a reduction in bone density. This leads to a detrimental condition called osteopenia. $\beta /$ near $\beta$-Ti alloys are gaining prominence due to their unique combination of high strength and low elastic modulus (14-85 GPa) [5]. Perfectly biocompatible $\beta /$ near $\beta$ Ti alloys with low elastic modulus form the most suitable artificial biomaterials for load-bearing applications.

$\beta$-Ti alloys demonstrate much lower moduli compared to other phases that may form in Ti-based alloys [5]. The new generation $\beta$-Ti alloys with no known toxic effects may be classified as binary systems (eg., Ti-Ta, Ti-Nb, Ti-Mo) [6-8], ternary systems (eg., Ti-Nb-Mo [9], Ti-Nb-Zr system [10-13], Ti-Nb-Sn system [14], Ti-Nb-Ta system $[15,16])$ and quaternary systems (eg., Ti-Nb-Zr-Sn system [17,18], Ti-Nb-Zr-Ta system [19-21]). Most of these alloys exhibit a low elastic modulus of $\leq 85 \mathrm{GPa}$ with very few systems demonstrating an incipient elastic modulus of $<50 \mathrm{GPa}$ (Ti-Nb-Zr-based systems) $[13,17,22-24]$.

Recently, additive manufacturing, in particular selective laser melting (SLM)/laserbased powder bed fusion process (LBPF), of such novel alloys has been the subject of intense research due to the ability of the process to manufacture near-net shaped parts with enhanced properties [25-29]. Although a multitude of research has undergone in the SLM of $\alpha$ or $\alpha+\beta$ type Ti alloys, only limited amount of literature is available on the SLM of $\beta /$ near- $\beta$ type 
alloys [30-36]. Laheurte et al. developed modified TNTZ alloys using "d-electron alloy design" that exhibited a low modulus in the range of $30 \mathrm{GPa}$ with reasonable strength retention [22]. Ti-Ta and Ti-Nb binary alloys produced by SLM showed an elastic modulus of $\sim 76 \mathrm{GPa}$ with enhanced mechanical properties [34,37]. Wang et al. fabricated $\mathrm{Ti}-\mathrm{Nb}$ binary alloys by SLM that exhibited an ultra-low modulus of $\sim 18 \mathrm{GPa}$ due to a maximum $\beta$ content but the alloys contained random porosity [30]. Ti2448 (Ti-24Nb-4Zr-8Sn) is another promising $\beta$-Ti alloy with a low modulus of $\sim 53 \mathrm{GPa}$ and a tensile strength of $\sim 660 \mathrm{MPa}$, produced by SLM [38]. However, highly volatile elements (like Sn) may vaporize and cause defects such as porosity leading to poor tensile and fatigue properties. Ti2448, produced by hot rolling and hot forging showed a low elastic modulus in the range of 45-55 GPa [33,3840]. SLM of dense Ti-alloys with predominant $\beta$ phase yielding in a low modulus, yet high strength, forms the core objective of currently ongoing studies.

Since elastic modulus is an intrinsic material property based on the crystal structure, crystal orientation and interatomic bond energies, the microstructure and phases should be manipulated with caution in order to achieve the desired modulus without compromising on the strength and corrosion attributes. In this study, we report for the first time the comparison between selective laser melted and spark plasma sintered $\beta$-Ti alloy that has been gaining huge popularity, namely Ti-35Nb-7Zr-5Ta or TNZT. Fabrication parameters such as the laser power and scanning speed have been optimized in order to obtain highly dense TNZT alloys. Detailed processing-structure-property relationships and the deformation behavior of the material are evaluated. Parts possessing an optimum strength-to-modulus balance have been produced with excellent repeatability. Spark plasma sintering (SPS) has also been carried out to fabricate the TNZT alloy in order to compare the microstructure-property correlations of the alloy fabricated by two different powder metallurgy techniques. In addition, the gas atomized powder used for the SLM process has also been used for the SPS process, to negate 
any differences in properties/microstructure that may arise from the differences in the raw material composition.

\section{Materials and Methods}

\subsection{Materials}

Pre-alloyed, gas-atomized Ti-35Nb-7Zr-5Ta (TNZT) powder (99.99\% purity; TOSOH, USA) was used to fabricate bulk specimens by SLM. The powder constituted spherical particles in the size range of $10-150 \mu \mathrm{m}\left(\mathrm{d}_{50}=63.7 \mu \mathrm{m}\right)$.

\subsection{Fabrication}

SLM was carried out at room temperature using a Realizer SLM 50 device, equipped with a fiber laser. The used SLM parameters are: (a) laser power: $100 \mathrm{~W}$; (b) scanning speed: 167 $\mathrm{mm} \mathrm{s}^{-1}$ for the volume and $250 \mathrm{~mm} \mathrm{~s}^{-1}$ for the contour; (c) layer thickness: $50 \mu \mathrm{m}$; (d) hatch spacing: $80 \mu \mathrm{m}$ and (e) hatch style rotation: $60^{\circ}$. The input energy density $\left(E\right.$ in $\mathrm{J} \mathrm{mm}{ }^{-3}$ ) was calculated using the following relation:

$$
E=\frac{P}{v * h * t}
$$

where $P$ is the laser power in Watt, $v$ is the scanning speed in $\mathrm{mm} \mathrm{s}^{-1}, h$ is the hatch spacing in $\mathrm{mm}$ and $t$ is the layer thickness in $\mathrm{mm}[41]$.

High purity (99.999\%) argon gas was used to purge the build chamber during the fabrication, in order to avoid oxidation of the specimens. For parameter optimization, density/hardness/microstructure evaluation, small cubes of dimensions $5 \times 5 \times 10 \mathrm{~mm}^{3}$ were built. For micro-tensile tests, dog-bone shaped specimens of total length $32 \mathrm{~mm}$, with a gauge length and width of $6 \mathrm{~mm}$ and $3 \mathrm{~mm}$, respectively were built directly and utilised. For compression tests, cylindrical specimens of length $6 \mathrm{~mm}$ and diameter $4 \mathrm{~mm}$ were printed. Support structures of height $2 \mathrm{~mm}$ were built between all the specimens and the substrate 
plate in order to ensure good mechanical stability of the SLM parts. All the samples were built on pure titanium substrate.

Densification via SPS was performed in a vacuum spark plasma sintering chamber (FCT Systeme $\mathrm{GmbH}$ ), enclosed in an argon-filled glovebox (mBraun MB200B), at $1200^{\circ} \mathrm{C}$ for 5 min under $50 \mathrm{MPa}$ uniaxial pressure.

\subsection{Characterization}

Density of the consolidated samples was measured using Archimedes principle on an analytical balance, Mettler Toledo ME204. The microstructure of the samples was determined by optical microscope, Zeiss Axiovert 25 and scanning electron microscope, Zeiss EVO MA15, equipped with an energy-dispersive X-ray spectroscopy (EDX) setup (Oxford Instruments). Samples for microstructural characterization were polished to mirrorfinish $(0.05 \mu \mathrm{m}$ colloidal silica suspension) and etched with Kroll's reagent. Structural analysis of the powders and bulk samples was carried out by X-ray diffraction (XRD) using a Rigaku SmartLab X-ray diffractometer equipped with $\mathrm{Cu}-\mathrm{K}_{\alpha}$ radiation $(\lambda: 1.5406 \AA)$, with a step size of $2 \theta=0.01^{\circ}$ in a reflection mode. Band contrast imaging and dislocation mapping were conducted by means of electron back-scattered diffraction (EBSD). After diamond polishing, the samples were prepared for EBSD by ion polishing using a Gatan PECS II ion polisher at $8 \mathrm{kV}, 5^{\circ}$ and $10 \mathrm{~min}$. EBSD was performed on a Zeiss Crossbeam 540 SEM, equipped with an Oxford Instruments detector. Microhardness tests were performed using Buehler Micromet2001 at a load of $500 \mathrm{gf}$ and a duration of $10 \mathrm{~s}$. The tensile tests were carried out on a Deban $5 \mathrm{kN}$ horizontal micro-tensile stage at a displacement rate of $0.42 \mathrm{~mm}$ $\min ^{-1}$. The strain was calculated based on the crosshead measurement, also considering corrections for machine compliance. Compression tests were carried out on Instron 8516 at a similar rate of crosshead movement. Elastic properties were measured by mean of ultrasonic techniques. Samples were cut with the thickness of around $0.5 \mathrm{~mm}$ and then polished 
maintaining parallel surfaces. Two ultrasonic transducers (20 and $100 \mathrm{MHz})$ were successively placed for measuring the dilatational and shear wave speeds. Subsequently, the elastic properties were calculated using standard techniques and the following functions:

$$
\begin{aligned}
& K=\rho\left(v_{1}^{2}-\frac{4}{3} v_{s}^{2}\right) \\
& v=\frac{v_{1}^{2}-2 v_{s}^{2}}{2\left(v_{1}^{2}-v_{s}^{2}\right)} \\
& E=\rho v_{s}^{2} \frac{3 v_{1}^{2}-4 v_{s}^{2}}{v_{1}^{2}-v_{s}^{2}}
\end{aligned}
$$

where $K$ is the bulk modulus, $E$ is the Young's modulus, $\rho$ is the density of the alloy, $v_{1}$ is the shear wave speed, $v_{s}$ is longitudinal wave speed.

\section{Results and Discussion}

\subsection{Analysis of pre-alloyed Ti-35Nb-7Zr-5Ta (TNZT) powders}

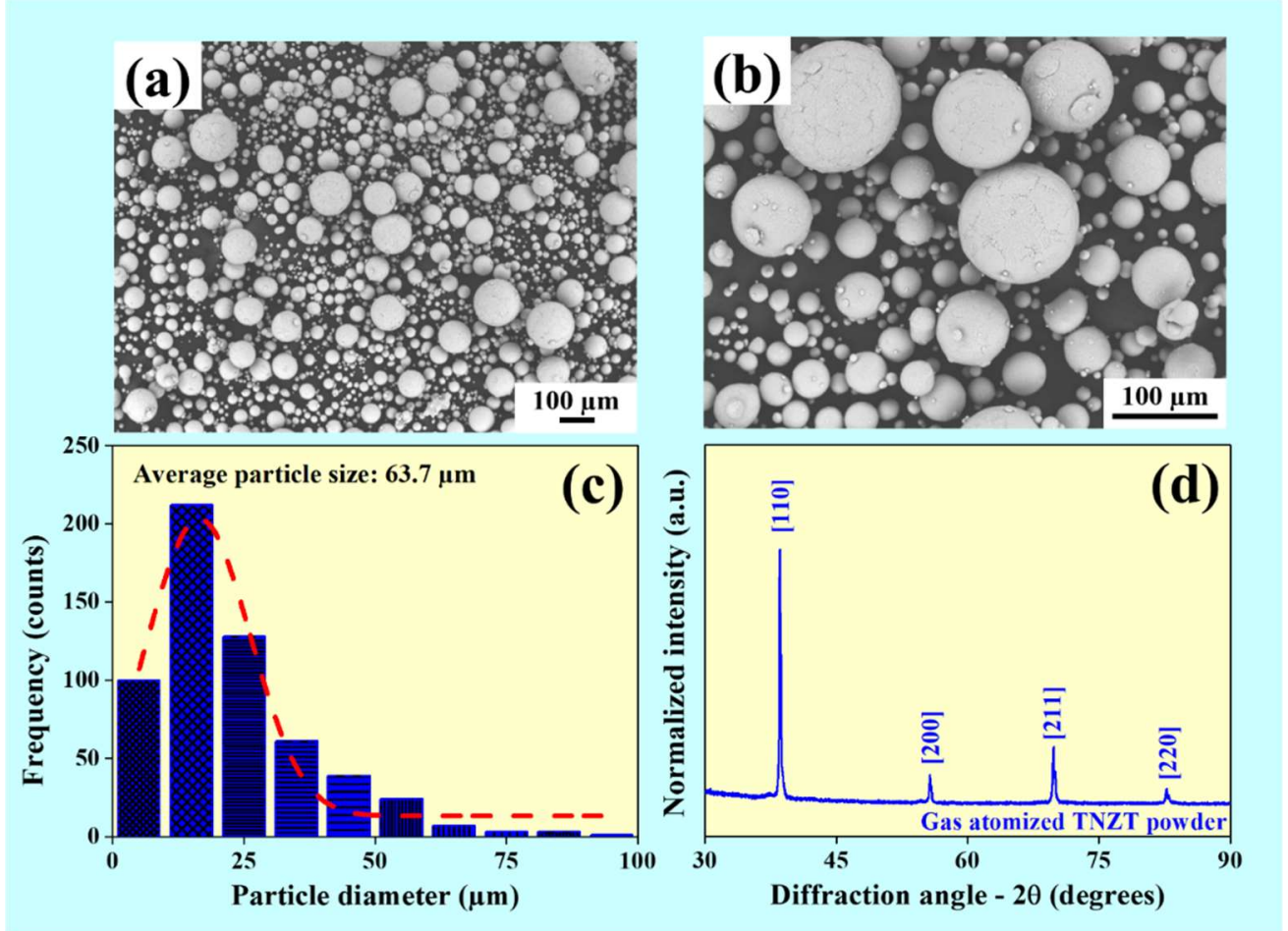

Fig. 1. Characterization of the TNZT pre-alloyed powder: Scanning electron micrographs at (a) lower and (b) higher magnifications showing spherical morphology and internal dendritic structure; (c) particle size distribution, and (d) x-ray diffraction pattern showing a single bcc phase. 
Gas atomized, pre-alloyed TNZT powders exhibit good flowability owing to their spherical shape, as evident from the scanning electron micrographs shown in Fig. 1(a). The internal structure of the powder particles is equiaxial dendritic, as observed from the bigger particles in Fig. 1(b). Ivanov et al., discussed about the minor chemical fluctuations among the participating elements inside these powder particles [42]. The measured $\mathrm{d}_{90}$ of TNZT powder observed from Fig. 1(c) is $64 \pm 10 \mu \mathrm{m}$ and accordingly, the layer thickness of the SLM process was set at $50 \mu \mathrm{m}$, considering the solidification shrinkage that may take place during solidification. The X-ray diffraction spectrum shown in Fig. 1(d) confirms the presence of a single-phase bcc $\beta$-Ti, which is in agreement with previous reports for the same material $[43,44]$.

\subsection{Densification of the SLM-TNZT alloy}

The appropriate parameters for obtaining nearly dense ( $>99.8 \%$ relative density) TNZT parts have been probed systematically by varying the two most important parameters: laser power and laser scan speed. The ensuing density contour maps are plotted as shown in the left panel of Fig. 2. The three dotted lines running across the middle of the maps represent the calculated energy densities $(E), 50 \mathrm{~J} \mathrm{~mm}^{-3}, 100 \mathrm{~J} \mathrm{~mm}^{-3}$ and $150 \mathrm{~J} \mathrm{~mm}^{-3}$, respectively from top to bottom. The map suggests that the highest relative density $(>99.5 \%$, red) was achieved for powders processed at $150 \mathrm{~J} \mathrm{~mm}^{-3}$, or more precisely at a laser power of at least $96.5 \mathrm{~W}$ and a scanning speed lower than $300 \mathrm{~mm} \mathrm{~s}^{-1}$. As we navigate towards the opposite corner of the map, i.e., at lower laser powers and higher scanning speeds, the densification worsens and the powders experience balling due to insufficient energy densities. The right panel of Fig. 2(a-i) shows the surface morphologies of the TNZT parts produced within the conditions enclosed in the dashed box on the density map. Fig. 2(g,h) indicates the presence of large, irregular shaped pores that form due to too low input energies and hence unmelted powder particles. This occurs generally when molten metal cannot fill the voids during the SLM process 
leading to irregular shaped sharp pores. Such incomplete melting by the laser leads to porosity resulting from the lack of complete fusion of powder particles. Fig. 2(i) shows the formation of much finer key holes, due to the supply of excess energy in the local areas. The narrow and deep localized melt pools yield hot vapors that are trapped in the form of fine bubbles. However, as shown in Fig. 2(f), the samples built at a laser power of $100 \mathrm{~W}$ and an exposure time of $60 \mu \mathrm{s}$ (scanning speed: $167 \mathrm{~mm} \mathrm{~s}^{-1}$ ) show the highest relative density of $99.87 \%\left(5.80 \pm 0.01 \mathrm{~g} \mathrm{~cm}^{-3}\right)$, with the theoretical density of the alloy being $5.81 \mathrm{~g} \mathrm{~cm}^{-3}$. For a constant laser current of $4000 \mathrm{~mA}$, deviation from the optimum scanning speed of $167 \mathrm{~mm} \mathrm{~s}^{-1}$ results either in severe splash/evaporation (at lower speeds) or balling/incomplete melting (at higher speeds), both resulting in lower densities $[45,46]$.

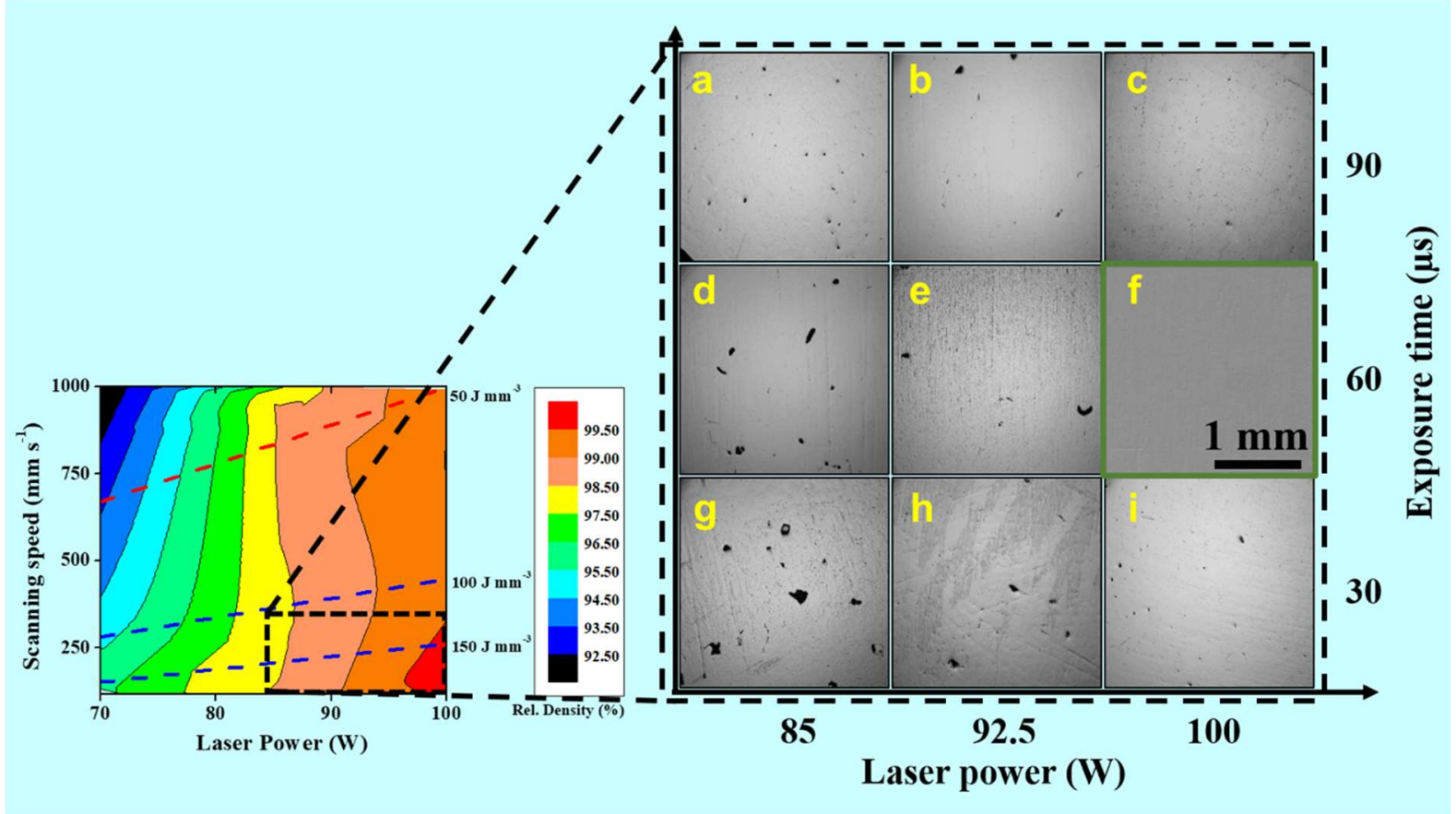

Fig. 2. (Left) Contour map of the relative density of TNZT parts produced by SLM as a function of laser power and scanning speed. Lines of constant energy density are indicated in the map. The dashed box indicates the process parameters used to produce near-dense parts. (Right) Optical microscopy images showing the surface morphologies of TNZT parts as a function of different laser powers and exposure times indicated within the box on the contour map; the point distance and hatch distance are set as $10 \mu \mathrm{m}$ and $80 \mu \mathrm{m}$, respectively.

\subsection{Microstructure, Phase constitution and Crystallography of SLM- and SPS TNZT Alloys}


The variations in the microstructure of the TNZT alloy, produced by SLM and SPS, are presented in Fig. 3. Fig. 3(a) shows the characteristic laser melt tracks of the SLM alloy sectioned normal to the build direction. Higher magnification images, as shown in Fig. 3(b,c), reveal the typical cellular grain structure with a size of $\sim 2 \mu \mathrm{m}$. The yellow lines in Fig. 3(b,c) outline the grain boundaries within the SLM alloy. The grains observed in the SLM materials is much smaller in size (in the range of 5-8 $\mu \mathrm{m}$ ). SPS alloy, on the other hand, shows larger ( $\sim 60 \mu \mathrm{m}$, one order of magnitude more than the grains in the SLM sample) and equiaxed grain structure as seen in Fig. 3(e-h). The difference in the grain structures and size is a result of constitutional supercooling in the SLM alloy, compared to lower cooling rates in the SPS alloy. However, in both the SLM and SPS TNZT alloys, only a single-phase microstructure is observed.

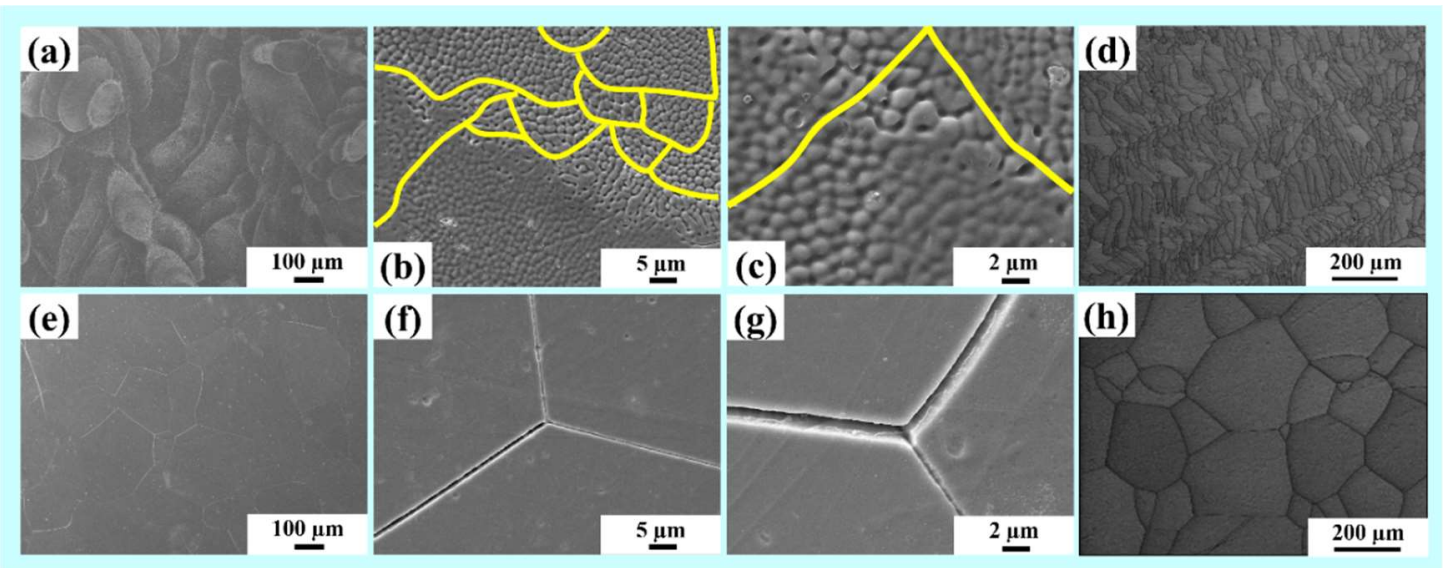

Fig. 3. (a-d) Scanning electron microscopy images showing the microstructure of polished and etched TNZT-SLM alloy and (e-h) TNZT-SPS alloy at different magnifications. 

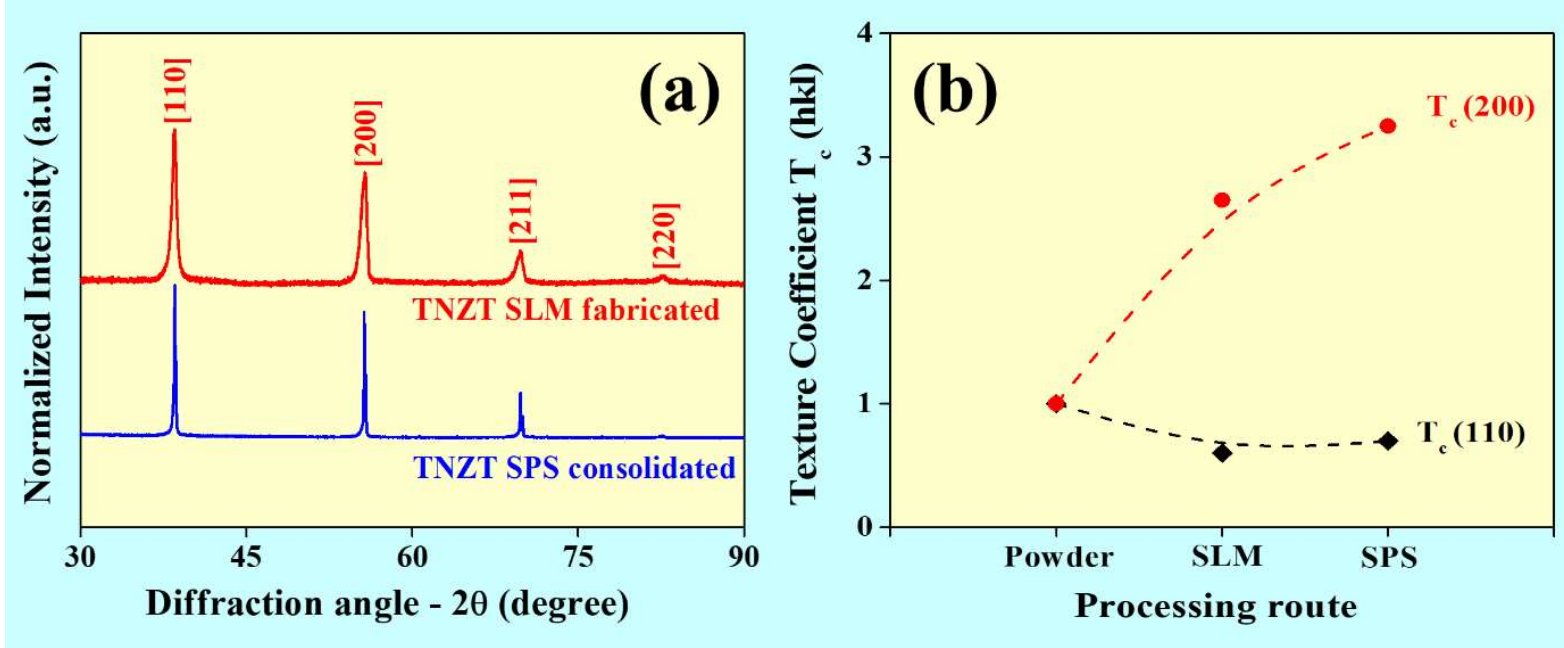

Fig. 4. (a) X-ray diffraction pattern for the SLM and SPS samples and (h) texture coefficients of the crystallographic planes (110) and (200).

The XRD patterns shown in Fig. 4(a) corroborate that both SLM and SPS samples exhibit a single $\beta$ (bcc) phase, similar to the precursor powder. The lattice parameters, calculated based on the distance between adjacent planes in the Miller indices (hkl) (calculated from the Bragg equation, $\lambda=2 \mathrm{~d} \operatorname{Sin} \theta)$, are found to be the similar for the SLM- $(0.33056 \mathrm{~nm})$ and SPS- $(0.33006 \mathrm{~nm})$ processed samples. Further, the strain and crystallite size are deduced from the XRD pattern by means of Williamson-Hall method [47]. As is evident from the XRD pattern for the SLM material, all the diffraction peaks show strain-induced broadening arising from crystal imperfections, which is a result of rapid cooling. Accordingly, the calculated strains $(\varepsilon)$ for the SLM- and SPS alloys are $36.64 \times 10^{-4}$ and $7.76 \times 10^{-4}$ respectively. The peak broadening is also associated with the smaller crystallite size in the SLM alloy. The crystallite sizes, deduced from Williamson-Hall method for SLM- and SPS TNZT alloys are $\sim 74 \mathrm{~nm}$ and $\sim 147 \mathrm{~nm}$ respectively. 


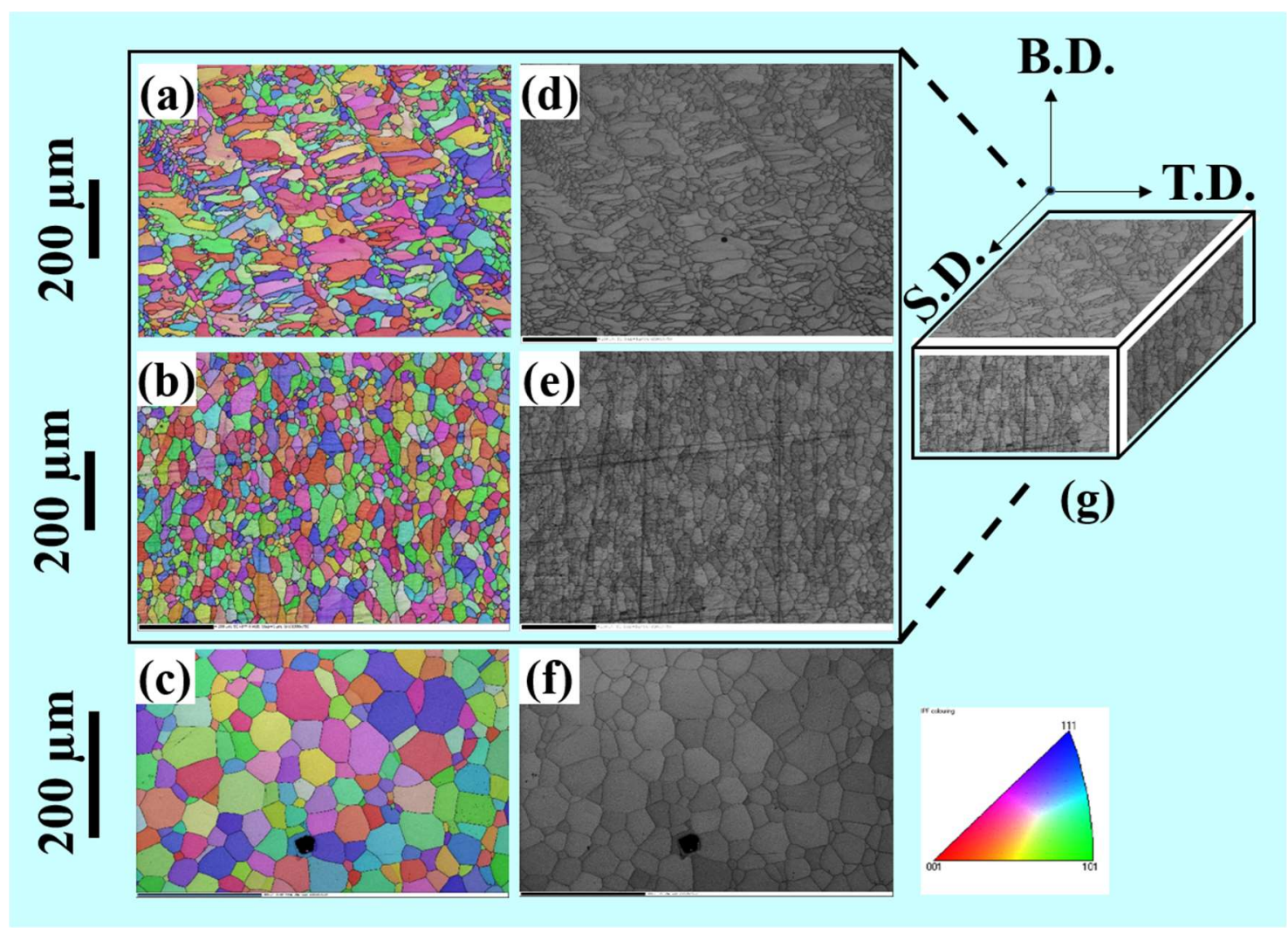

Fig. 5. Electron back scattered diffraction orientation maps examined from the (a) build- and (b) transverse directions of the SLM TNZT sample, (c) TNZT-SPS sample; (d-f) corresponding band contrast maps; (g) Isometric view for the orthogonal planes of SLM TNZT cube showing the microstructure evolution in the SLM parts.

In addition to the microstructure and phase analysis of polycrystalline materials, determination of texture or preferential orientation accounts for the anisotropic properties of the material. Any preferred crystal orientation in a material is closely related to the processing conditions. The XRD pattern suggests that both SLM- and SPS alloys exhibit texture for the planes (110) and (200). The extent of texture between these planes can be quantified using the texture coefficient, which is given as [48]:

$$
T_{C}(h k l)=\frac{I(h k l) / I_{o}(h k l)}{\left(\frac{1}{N}\right)\left[\sum_{N} I(h k l) / I_{O}(h k l)\right]}
$$

where $T_{C}(\mathrm{hkl})$ is the texture coefficient of the (hkl) plane, $I$ is the measured intensity, $I_{O}$ is the standard intensity from reference and $N$ is the number of diffraction peaks. As evident from Fig. 4(b), deviation of $T_{c}(110)$ and $T_{c}(200)$ from unity indicates the presence of preferential orientation in the crystals for both SLM- and SPS alloys. 
Fig. 5 illustrates the detailed crystallographic orientations and grain structure, as revealed by EBSD. Fig. 5(a) represents the orientation map of the SLM TNZT sample in the build direction, composed of elongated grains along the melt tracks, while the melt track boundaries feature smaller equiaxed grains. For the same sample, a complete equiaxed grain structure is evident in the transverse direction, as shown in Fig. 5(b). The disparity in the grain size, grain shape and orientations result in the anisotropic behavior of the SLM alloys. Fig. 5(c) demonstrates a conventional planar microstructure comprising larger grains (note the different scale bars for the SLM- and SPS alloys) for the SPS TNZT sample. Some texturing is observed, but is not clearly evident from the maps. Fig. 5(d-f) represent the corresponding band contrast maps for the images shown through Fig. 5(a-c). Fig. 5(g) shows an isometric view for the orthogonal planes building up the SLM alloy.

Fig. 6(a) shows the grain size distribution of the SLM- and SPS TNZT alloys. While the SPS TNZT alloy shows a wide distribution of grain size ranging from $\sim 10 \mu \mathrm{m}$ to $>400 \mu \mathrm{m}$, the SLM TNZT alloy shows a narrower distribution from $<10 \mu \mathrm{m}$ to $\sim 100 \mu \mathrm{m}$, which was anticipated. The finer grain size anticipated for the SLM TNZT alloy (in the build- or transverse directions) is a consequence of rapid cooling, according to the exponentially decreasing (inverse) relationship between the grain size and cooling rate $[47,48]$. 


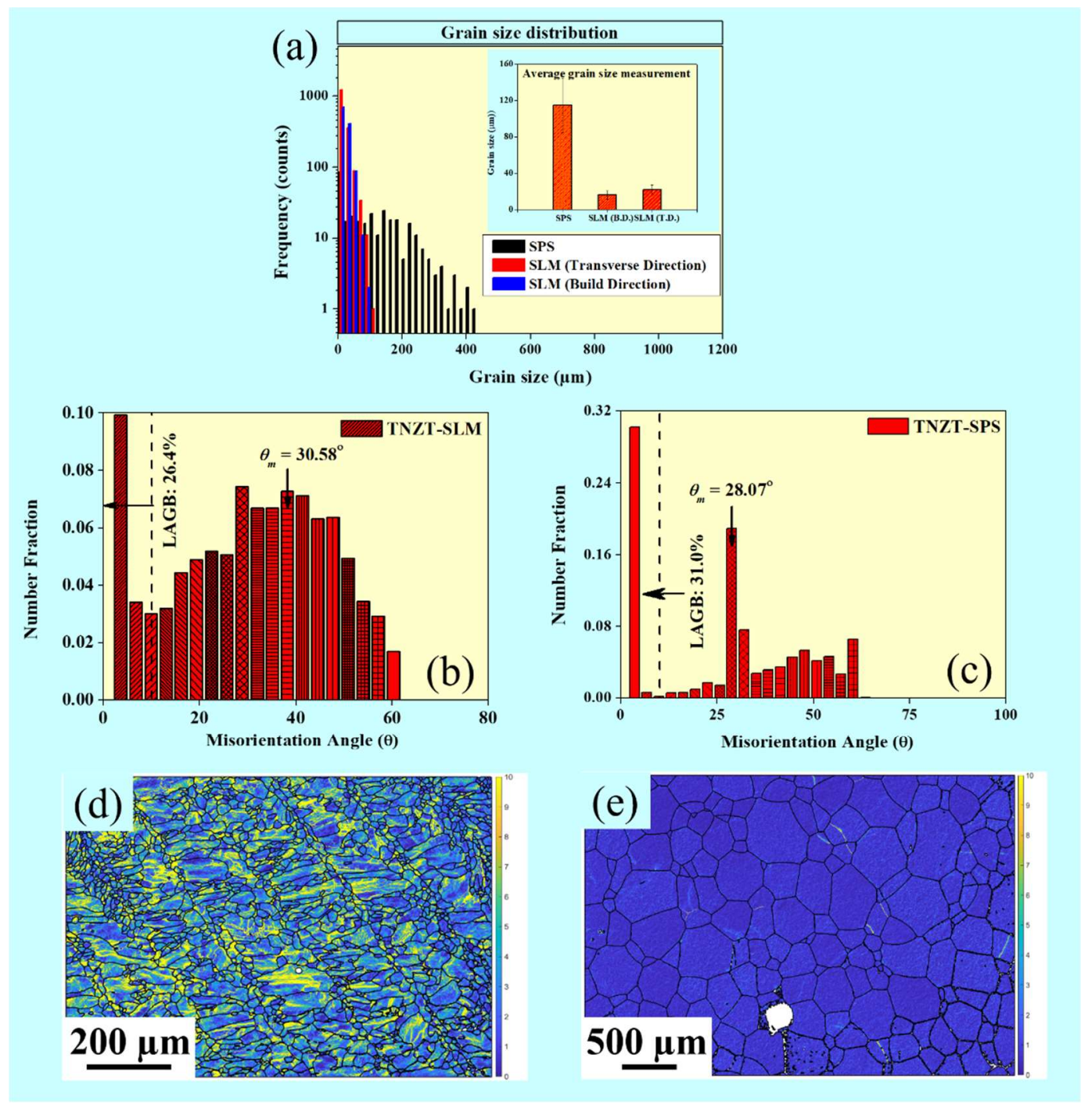

Fig. 6: Electron back scattered diffraction histograms of (a) circle equivalent grain sizes for the SLM TNZT (Build direction ' $Z$ ' and Transverse direction ' $Y$ ') and SPS-TNZT with the inset showing average grain size; Misorientation distribution of (b) SLM-TNZT and (c) SPSTNZT alloys, GND density distribution of the (d) SLM-TNZT and (e) SPS-TNZT alloys.

The inset in Fig. 6(a) shows that the average grain sizes for the SLM- and SPS TNZT alloys are $20 \pm 13 \mu \mathrm{m}$ (build direction) $/ 18 \pm 14 \mu \mathrm{m}$ (transverse direction) and $115 \pm 30 \mu \mathrm{m}$, respectively. Fig. $6(\mathrm{~b}, \mathrm{c})$ shows the degree of misorientation in the SLM- and SPS TNZT samples in the as-fabricated condition. A threshold misorientation of $10^{\circ}$ had been chosen to distinguish low angle grain boundaries (LAGB) and high angle grain boundaries (HAGB). The fraction of LAGB for both the SLM and SPS TNZT samples is about $31 \%$, while HAGB constitutes around 69\%. The mean misorientation angle for the SLM and SPS samples are found to be $\sim 24.72^{\circ}$ and $\sim 28.07^{\circ}$ respectively. From the measured Euler angles, and thus 
misorientation data, it is possible to fit and obtain total GND (geometrically necessary dislocation) density as described by Pantleon [49]. Fig. 6(d,e) shows a 2D GND (geometrically necessary dislocation) density distribution on the SLM- and SPS TNZT alloys. The scale bar reads between 0 to 10 in units of dislocation lines $/ \mu \mathrm{m}^{2}$ ). It is to be noted that the noise floor for this method is in the order of 1 line $/ \mu \mathrm{m}^{2}$. It is clear from Fig. $6(\mathrm{~d}, \mathrm{e})$ that the GND density in the SLM TNZT is markedly higher than the SPS alloy, resulting in a probable mechanical strengthening of the former.

\subsection{Mechanical characterization of the SLM-TNZT alloy}

The average microhardness of the samples is measured as $205 \pm 10 \mathrm{HV}$. Fig. 7(a) shows the room temperature true stress-true strain curves of the SLM TNZT alloy under tension. The yield strength ( $0.2 \%$ offset) of the SLM TNZT alloy is $309 \mathrm{MPa}$ and a dip in the curve just after the onset of yielding can be attributed to the classic yield point phenomenon that is commonly observed in case of metals/alloys exhibiting a bcc crystal structure [50]. The alloy exhibits an ultimate tensile strength (UTS) of $631 \mathrm{MPa}$, which is remarkably high considering its extremely low modulus. The elastic modulus, as determined by the ultrasonic technique, is $\sim 81 \mathrm{GPa}$, which is far less than that of the existing and most of the competing biomaterials processed by SLM [34,51-54]. Low elastic modulus for the SLM-TNZT alloy may be ascribed to (a) bcc crystal structure, (b) mild preferred orientation along the cube face $\{200\}$ and (c) fine grain structure, all of them contributing to weak interatomic forces. Fig. 7(b) shows the compression stress-strain curves for the alloy. The elastic modulus and yield strength under compression for the alloy are determined as $20 \pm 2 \mathrm{GPa}$ and $528 \pm 8 \mathrm{MPa}$, respectively. Fig. 7(c,d) shows the fracture morphology of the SLM TNZT tensile specimens. The fracture surface shows dimples and cleavages, indicating a classic ductile fracture. The fracture most likely propagates through the hatch overlaps. Plastic deformation may predominantly occur via grain rotation due to a high volume of grain boundaries. Hence, 
SLM TNZT alloy exhibits high ductility (14-15\% until fracture; $~ 9.4 \%$ until the onset of necking) under tension and high deformability under compression, while simultaneously maintaining superior strength via at least three mechanisms: solid solution strengthening due to the presence of various alloying elements, grain boundary strengthening facilitated by a fine grain structure, and a high dislocation density.
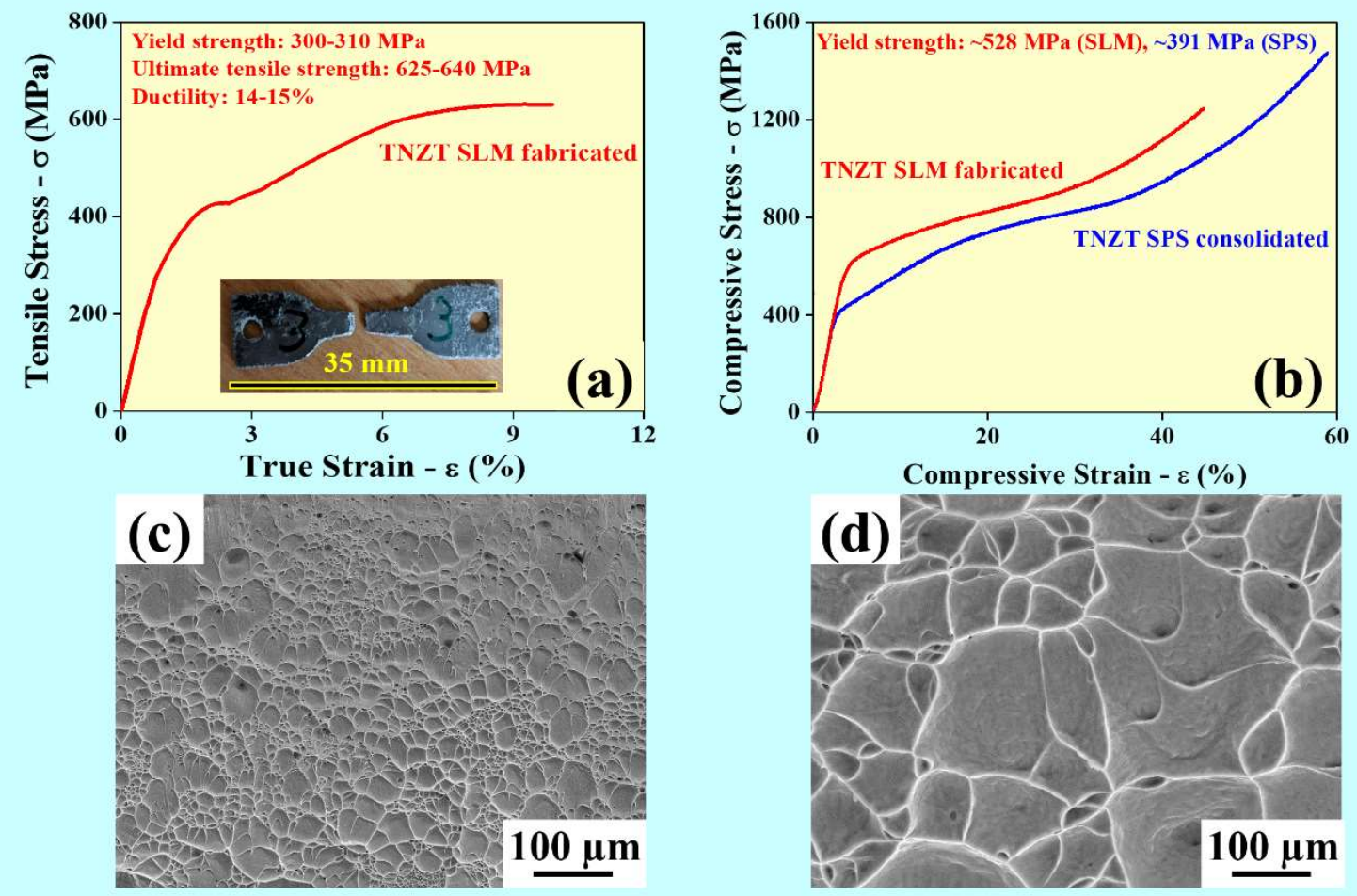

Fig. 7. (a) Room temperature true stress-strain curve plot of TNZT-SLM sample; (b) Room temperature compressive stress-strain plot of SLM and SPS fabricated TNZT samples; (c) and (d) fracture surface of the TNZT-SLM tensile specimens at low and high magnifications respectively.

Fig. 8 shows an overview of the tensile strength and elastic modulus of the most common metallic biomaterials for load-bearing applications [34,51-54]. For an ideal metallic biomaterial, it is important to maintain a low modulus while exhibiting a high strength and moderate ductility. CoCrMo alloys exhibit the highest strength but also exhibit excessively high elastic modulus. Titanium-based alloys exhibit the most optimum combination of strength and modulus, while the SLM-TNZT alloy developed in the present study exhibits a perfect combination of high strength and a desirably low elastic modulus, thus showing a 
huge potential to replace the existing metallic implants for long-term functionality coupled with near-net shape processing. The elastic modulus of porous (Ti) alloys can be much lower than their dense counterparts and can be manipulated in a wide range by varying the degree of porosity. Hence, only solid (dense) alloys have been mapped in Fig. 8, while porous alloys have been excluded from the mapping.

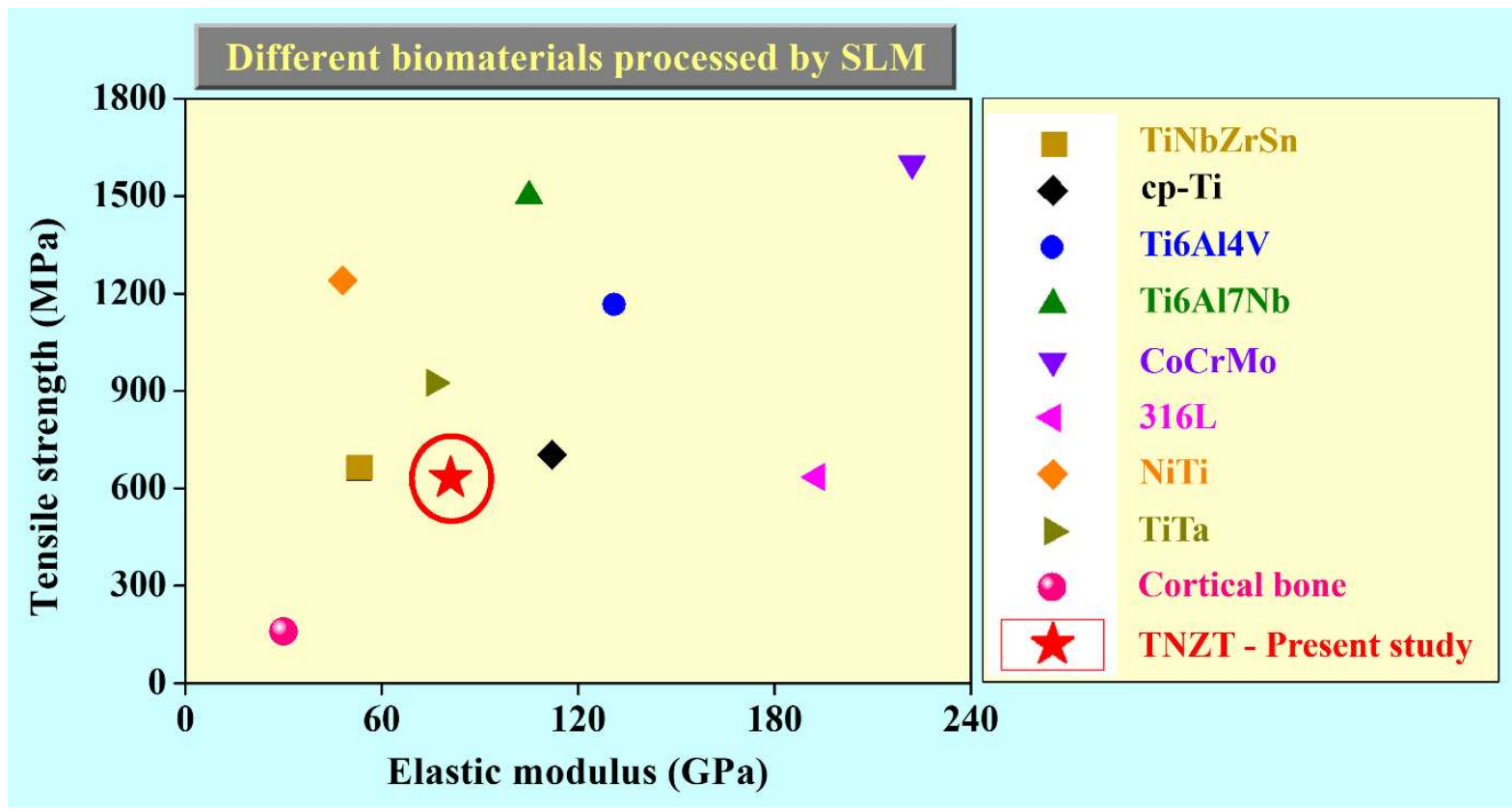

Fig. 8. Overview of the tensile strength and elastic modulus of the state-of-the-art metallic biomaterials processed by SLM, in comparison with the present alloy and natural bone.

\section{Conclusions}

In this study, we have shown that dense Ti-35Nb-7Zr-5Ta (TNZT) alloys can be processed by SLM. The unique microstructure, single $\beta$ (bcc) phase constitution lead to excellent mechanical properties favorable for biomedical applications. The as-printed TNZT alloy shows high densification ( $>99.8 \%$ ) achievable at $\sim 150 \mathrm{~J} \mathrm{~mm}^{-3}$ and possesses a tensile strength of $\sim 631 \mathrm{MPa}$ and a low elastic modulus of $\sim 81 \mathrm{GPa}$. The microstructure is composed of fine, equiaxed, as well as narrow elongated grains, along the laser tracks, with an average size of 3-80 $\mu \mathrm{m}$. The excellent mechanical strength exhibited by the SLM TNZT alloy is attributed to the high amount of local strains, as a result of rapid cooling, and a high density of dislocation network. The alloy exhibited a low modulus, ideal for biomedical 
applications, owing to the $\{200\}$ preferred orientation of the bcc crystal structure and a large grain boundary area. The remarkable strength, good ductility and a low modulus makes the SLM-processed TNZT alloy an ideal material for load-bearing biomedical applications.

\section{Acknowledgments}

This work was supported by the European Regional Development Fund (ASTRA6-6, ASTRA35-6 and MOBERC15). The authors would like to thank Dr. Vitali Podgurski, Mr. Andrei Bogatov, Mr. Asad Alamgir Shaikh, Dr. Mart Viljus, Dr. Märt Kolnes, Mr. Rainer Traksmaa, Mr. Endel Esinurm and Ms. Laivi Väljaots for extending research facilities and helping to improve the research outcome with stimulating discussions.

\section{References}

[1] D. Kuroda, M. Niinomi, M. Morinaga, Y. Kato, T. Yashiro, Design and mechanical properties of new $\beta$ type titanium alloys for implant materials, Mater. Sci. Eng. A 243 (1998) 244-249. https://doi.org/10.1016/S0921-5093(97)00808-3

[2] K.H.W. Seah, R. Thampuran, S.H. Teoh, The influence of pore morphology on corrosion, Corros. Sci. 40 (1998) 547-556. https://doi.org/10.1016/S0010-938X(97)00152-2

[3] Y. Okazaki, E. Nishimura, H. Nakada, K. Kobayashi, Surface analysis of Ti-15Zr-4Nb4Ta alloy after implantation in rat tibia, Biomaterials 22 (2001) 599-607. https://doi.org/10.1016/S0142-9612(00)00221-0

[4] G.R. Parr, L.K. Gardner, R.W. Toth, Titanium: The mystery metal of implant dentistry: Dental materials aspects, J. Prosthet. Dent. $54 \quad$ (1985) 410-414. https://doi.org/10.1016/0022-3913(85)90562-1

[5] M.T. Mohammed, Z.A. Khan, A.N. Siddiquee, Beta titanium alloys: the lowest elastic modulus for biomedical applications: a review, Int. J. Chem. Mol. Nucl. Mater. Metall. Eng. 8 (2014) 726-731. doi.org/10.5281/zenodo.1094481 
[6] Y.L. Zhou, M. Niinomi, Ti-25Ta alloy with the best mechanical compatibility in Ti-Ta alloys for biomedical applications, Mater. Sci. Eng. C 29 (2009) 1061-1065. https://doi.org/10.1016/j.msec.2008.09.012

[7] C.R.M. Afonso, G.T. Aleixo, A.J. Ramirez, R. Caram, Influence of cooling rate on microstructure of Ti-Nb alloy for orthopedic implants, Mater. Sci. Eng. C 27 (2007) 908913. https://doi.org/10.1016/j.msec.2006.11.001

[8] L.D. Zardiackas, D.W. Mitchell, J.A. Disegi, In Medical applications of titanium and its alloys: the material and biological issues. (1996) ASTM International. https://doi.org/10.1520/STP16070S

[9] Y. Al-Zain, H.Y. Kim, H. Hosoda, T.H. Nam, S. Miyazaki, Shape memory properties of Ti-Nb-Mo biomedical alloys, Acta Mater. $58 \quad$ (2009) 4212-4223. https://doi.org/10.1016/j.actamat.2010.04.013

[10] A.K. Mishra, J.A. Davidson, R.A. Poggie, P. Kovacs, T.J. Fitzgerald, In: Brown SA, Lemons JE, editors. Medical Applications of Titanium and its Alloys, ASTM STP. West Conshohocken, PA: ASTM International (1996).

[11] M. Takahashi, E. Kobayashi, H. Doi, T. Yoneyama, H. Hamanaka, Grindability of dental cast Ti-Zr alloys, J. Jpn. I. Met. 64 (2000) 1120-1126.

[12] Q. Li, M. Niinomi, M. Nakai, Z. Cui, S. Zhu, X. Yang, Improvements in the superplasticity and change in deformation mode of $\beta$-type $\mathrm{TiNb}_{24} \mathrm{Zr}_{2}$ alloys caused by aging treatments, Metall. Mater. Trans. A $42 \quad$ (2011) 2843-2849. https://doi.org/10.1007/s11661-011-0713-0

[13] L.W. Ma, H.S. Cheng, C.Y. Chung, Effect of thermo-mechanical treatment on superelastic behavior of Ti-19Nb-14Zr (at.\%) shape memory alloy, Intermetallics 32 (2013) 44-50. https://doi.org/10.1016/j.intermet.2012.07.024 
[14] K. Miura, N. Yamada, S. Hanada, T.K. Jung, E. Itoi, The bone tissue compatibility of a new Ti-Nb-Sn alloy with a low Young's modulus, Biomater. 7 (2011) 2320-2326. https://doi.org/10.1016/j.actbio.2011.02.008

[15] H.Y. Kim, S. Hashimoto, J.I. Kim, T. Inamura, H. Hosoda, S. Miyazaki, Effect of Ta addition on shape memory behavior of Ti-22Nb alloy, Mater. Sci. Eng. A 417 (2006) 120-128. https://doi.org/10.1016/j.msea.2005.10.065

[16] J. Málek, F. Hnilica, J. Veselý, B. Smola, S. Bartáková, J. Vaněk, The influence of chemical composition and thermo-mechanical treatment on Ti-Nb-Ta-Zr alloys, Mater. Des. 35 (2012) 731-740. https://doi.org/10.1016/j.matdes.2011.10.030

[17] Y.L. Hao, S.J. Li, S.Y. Sun, C.Y. Zheng, R. Yang, Elastic deformation behavior of Ti24Nb-4Zr-7.9Sn for biomedical applications, Acta Biomater. 3 (2007) 277-286. https://doi.org/10.1016/j.actbio.2006.11.002

[18] Z. Guo, J. Fu, Y.Q. Zhang, Y.Y. Hu, Z.G. Wu, L. Shi, M. Sha, S.J. Li, Y.L. Hao, R. Yang, Early effect of Ti-24Nb-4Zr-7.9Sn intramedullary nails on fractured bone, Mater. Sci. Eng. C 29 (2009) 963-968. https://doi.org/10.1016/j.msec.2008.08.019

[19] P. Majumdar, S.B. Singh, M. Chakraborty, Elastic modulus of biomedical titanium alloys by nano-indentation and ultrasonic techniques-A comparative study, Mater. Sci. Eng. A 489 (2008) 419-425. https://doi.org/10.1016/j.msea.2007.12.029

[20] L. Wang, W. Lu, J. Qin, F. Zhang, D. Zhang, Effect of precipitation phase on microstructure and superelasticity of cold-rolled beta titanium alloy during heat treatment, $\quad$ Mater. $\quad$ Des. $30 \quad$ (2009) 3873-3878. https://doi.org/10.1016/j.matdes.2009.03.042

[21] Q. Wei, L. Wang, Y. Fu, J. Qin, W. Lu, D. Zhang, Influence of oxygen on microstructure and mechanical properties of Ti-Nb-Ta-Zr alloy, Mater. Des. 32 (2011) 2934-2939. https://doi.org/10.1016/j.matdes.2010.11.049 
[22] P. Laheurte, F. Prima, A. Eberhardt, T. Gloriant, M. Wary, E. Patoor, Mechanical properties of low modulus $\beta$ titanium alloys designed from the electronic approach, J. Mech. Behav. Biomed. Mater. $3 \quad$ (2010) 565-573. https://doi.org/10.1016/j.jmbbm.2010.07.001

[23] T.K. Jung, H. Matsumoto, T. Abumiya, N. Masahashi, M.S. Kim, S. Hanada, Mechanical properties-graded $\mathrm{Ti}$ alloy implants for orthopaedic applications: Multiscale, multifunctional and functionally graded materials, Mater. Sci. Forum 631 (2010) 205210. https://doi.org/10.4028/www.scientific.net/MSF.631-632.205

[24] L. Wang, L. Xie, Y. Lv, L.C. Zhang, L. Chen, Q. Meng, J. Qu, D. Zhang, W. Lu, Microstructure evolution and superplastic behavior in Ti-35Nb-2Ta-3Zr alloy processed by friction stir processing, Acta Mater. $131 \quad$ (2017) 499-510. https://doi.org/10.1016/j.actamat.2017.03.079

[25] K.G. Prashanth, S. Scudino, J. Eckert, Defining tensile properties of Al-12Si parts produced by selective laser melting, Acta Mater. $126 \quad$ (2017) 25-35. https://doi.org/10.1016/j.actamat.2016.12.044

[26] J. Suryawanshi, K.G. Prashanth, S. Scudino, J. Eckert, O. Prakash, U. Ramamurty, Simultaneous enhancements of strength and toughness in an Al-12Si alloy synthesized using selective laser melting, Acta Mater. $115 \quad$ (2016) 285-294. https://doi.org/10.1016/j.actamat.2016.06.009

[27] J. Suryawanshi, K.G. Prashanth, U. Ramamurty, Mechanical behavior of selective laser melted 316L stainless steel, Mater. Sci. Eng. A, $696 \quad$ (2017) 113-121. https://doi.org/10.1016/j.msea.2017.04.058

[28] K.G. Prashanth, S. Scudino, H. J. Klauss, K.B. Surreddi, L. Löber, Z. Wang, A.K. Chaubey, U. Kühn, J. Eckert, Microstructure and mechanical properties of Al-12Si 
produced by selective laser melting: Effect of heat treatment, Mater. Sci. Eng. A 590 (2014) 153-160. https://doi.org/10.1016/j.msea.2013.10.023

[29] S. Scudino, C. Unterdoerfer, K.G. Prashanth, H. Attar, N. Ellendt, V. Uhlenwinkel, J. Eckert, Additive manufacturing of Cu-10Sn bronze, Mater. Lett. 156 (2015) 202-204. https://doi.org/10.1016/j.matlet.2015.05.076

[30] Q. Wang, C. Han, T. Choma, Q. Wei, C. Yan, B. Song, Y. Shi, Effect of Nb content on microstructure, property and in vitro apatite-forming capability of Ti-Nb alloys fabricated via selective laser melting, Mater. Des. $126 \quad$ (2017) 268-277. https://doi.org/10.1016/j.matdes.2017.04.026

[31] T. Ishimoto, K. Hagihara, K. Hisamoto, S.H. Sun, T. Nakano, Crystallographic texture control of beta-type Ti-15Mo-5Zr-3Al alloy by selective laser melting for the development of novel implants with a biocompatible low Young's modulus, Scripta Mater. 132 (2017) 34-38. https://doi.org/10.1016/j.scriptamat.2016.12.038

[32] K. Zhuravleva, M. Bönisch, K.G. Prashanth, U. Hempel, A. Helth, T. Gemming, M. Calin, S. Scudino, L. Schultz, J. Eckert, Production of porous $\beta$-type Ti-40Nb alloy for biomedical applications: Compression of selective laser melting and hot pressing, Mater. 6 (2013) 5700-5712. https://doi.org/10.3390/ma6125700

[33] Y.J. Liu, X.P. Li, L.C. Zhang, T.B. Sercombe, Processing and properties of topologically optimised biomedical Ti-24Nb-4Zr-8Sn scaffolds manufactured by selective laser melting, Mater. Sci. $\quad$ Eng. $\quad A \quad 642 \quad$ (2015) 268-278. https://doi.org/10.1016/j.msea.2015.06.088

[34] S.L. Sing, W.Y. Yeong, F.E. Wiria, Selective laser melting of titanium alloy with 50 wt.\% tantalum: Microstructure and mechanical properties, J. Alloys Compd. 660 (2016) 461-470. https://doi.org/10.1016/j.jallcom.2015.11.141 
[35] N. Kang, Y. Li, X. Lin, E. Feng, W. Huang, Microstructure and tensile properties of TiMo alloys manufactured via using laser powder bed fusion, J. Alloys Compd. 771 (2019) 877-884. https://doi.org/10.1016/j.jallcom.2018.09.008

[36] S. Huang, S. L. Sing, G. Delooze, R. Wilson, W. Y. Yeong, Laser powder bed fusion of titanium-tantalum alloys: Compositions and designs for biomedical applications. J Mech Behav Biomed Mater. 108 (2020) 103775. https://doi.org/10.1016/j.jmbbm.2020.103775

[37] M. Fischer, D. Joguet, G. Robin, L. Peltier, P. Laheurte, In situ elaboration of a binary $\mathrm{Ti}-26 \mathrm{Nb}$ alloy by selective laser melting of elemental titanium and niobium mixed powders, Mater. Sci. $\quad$ Eng. $\quad$ C $\quad 62 \quad$ (2016) 852-859. https://doi.org/10.1016/j.msec.2016.02.033

[38] L.C. Zhang, D. Klemm, J. Eckert, Y.L. Hao, T.B. Sercombe, Manufacture by selective laser melting and mechanical behavior of a biomedical Ti-24Nb-4Zr-8Sn alloy, Scripta Mater. 65 (2011) 21-24. https://doi.org/10.1016/j.scriptamat.2011.03.024

[39] L.C. Zhang, T.B. Sercombe, Selective laser melting of low-modulus biomedical Ti24Nb-4Zr-8Sn alloy: Effect of laser point distance, Key Eng. Mater. 520 (2012) 226-233. https://doi.org/10.4028/www.scientific.net/KEM.520.226

[40] P. Qin, Y. Liu, T. B. Sercombe, Y. Li, C. Zhang, C. Cao, H. Sun, L. C. Zhang, Improved corrosion resistance on selective laser melting produced $\mathrm{Ti}-5 \mathrm{Cu}$ alloy after heat treatment, ACS Biomater. Sci. Eng. 4, $7 \quad$ (2018) 2633-2642. https://doi.org/10.1021/acsbiomaterials.8b00319

[41] K.G. Prashanth, S. Scudino, T. Maity, J. Das, J. Eckert, Is the energy density a reliable parameter for materials synthesis by selective laser melting? Mater. Res. Lett. 5 (2017) 386-390. https://doi.org/10.1080/21663831.2017.1299808

[42] E. Ivanov, E. del Rio, I. Kapchemnko, M. Nyström, J. Kotila, Development of biocompatible beta $\mathrm{Ti}$ alloy powders for additive manufacturing for application in patient- 
specific orthopaedic implants, Key Eng. Mater. $770 \quad$ (2018) 9-17. https://doi.org/10.4028/www.scientific.net/KEM.770.9

[43] P.L. Ferrandini, F.F. Cardoso, S.A. Souza, C.R. Afonso, R. Caram, Aging response of Ti-35Nb-7Zr-5Ta and Ti-35Nb-7Ta alloys, J. Alloys Compd. 433 (2007) 207-210. https://doi.org/10.1016/j.jallcom.2006.06.094

[44] R. Banerjee, S. Nag, S. Samuel, H. L. Fraser, Laser deposited Ti-Nb-Zr-Ta orthopedic alloys, J. Biomed. Mater. Res. A 78 (2006) 298-305. https://doi.org/10.1002/jbm.a.30694

[45] Y.H. Zhou, W.P. Li, D.W. Wang, L. Zhang, K. Ohara, J. Shen, T. Ebel, M. Yan, Selective laser melting enabled additive manufacturing of Ti-22Al-25Nb intermetallic: Excellent combination of strength and ductility, and unique microstructural features associated, Acta Mater. 173 (2019) 117-129. https://doi.org/10.1016/j.actamat.2019.05.008

[46] D. Wang, C. Yu, X. Zhou, J. Ma, W. Liu, Z. Shen, Dense pure tungsten fabricated by selective laser melting, Appl. Sci. 7 (2017) 430. https://doi.org/10.3390/app7040430

[47] A.K. Zak, W.H.A. Majid, M.E. Abrishami, R. Yousefi, X-ray analysis of ZnO nanoparticles by William-Hall and size-strain plot methods, Solid State Sci. 13 (2011) 251-256. https://doi.org/10.1016/j.solidstatesciences.2010.11.024

[48] J.A.R. Márquez, C.M.B. Rodríguez, C.M. Herrera, E.R. Rosas, O.Z. Angel, O.T. Pozos, Effect of surface morphology of $\mathrm{ZnO}$ electrodeposited on photocatalytic oxidation of methylene blue dye part I: analytical study, Int. J. Electrochem. Sci. 6 (2011) 4059-4069.

[49] W. Pantleon, Resolving the geometrically necessary dislocation content by conventional electron backscattering diffraction, Scripta Mater. 58 (2008) 994-997. https://doi.org/10.1016/j.scriptamat.2008.01.050

[50] R.E. Reed-Hill, R. Abbaschian, Physical Metallurgy Principles, 3rd ed. Boston, MA: PWS Publishing Company 284-285 (1994). 
[51] J. Čapek, M. Machova, M. Fousova, J. Kubásek, D. Vojtěch, J. Fojt, E. Jablonska, J. Lipov, T. Ruml, Highly porous, low elastic modulus 316L stainless steel scaffold prepared by selective laser melting, Mater. Sci. Eng. C 69 (2016) 631-639. https://doi.org/10.1016/j.msec.2016.07.027

[52] P. Fernandez-Zelaia, V. Nguyen, H. Zhang, A. Kumar, S. N. Melkote, The effect of material anisotropy on secondary processing of additively manufactured $\mathrm{CoCrMo}$, Addit. Manuf. 29 (2019) 100764. https://doi.org/10.1016/j.addma.2019.06.015

[53] E. Chlebus, B. Kuźnicka, T. Kurzynowski, B. Dybała, Microstrcuture and mechanical behavior of Ti-6Al-7Nb alloy produced by selective laser melting, Mater. Chara. 62 (2011) 488-495. https://doi.org/10.1016/j.matchar.2011.03.006

[54] M.H. Elahinia, M. Hashemi, M. Tabesh, S.B. Bhaduri, Manufacturing and processing of NiTi implants: A review, Prog. Mater. Sci. $57 \quad$ (2012) 911-946. https://doi.org/10.1016/j.pmatsci.2011.11.001 